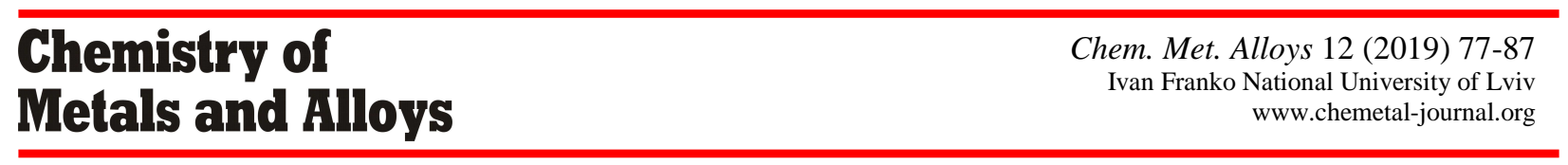

\title{
Electrochemical hydrogenation of solid solutions based on the intermetallic compound $\mathrm{SmNi}_{5}$
}

\author{
Vasyl KORDAN ${ }^{1}$, Ivan TARASIUK ${ }^{1}$, Iryna STETSKIV ${ }^{1}$, Roman $_{\text {SERKIZ }}^{2}$, Volodymyr PAVLYUK ${ }^{1}$ \\ ${ }^{1}$ Department of Inorganic Chemistry, Ivan Franko National University of Lviv, \\ Kyryla i Mefodiya St. 6, 79005 Lviv, Ukraine \\ ${ }^{2}$ Scientific-Technical and Educational Centre of Low Temperature Studies, \\ Ivan Franko National University of Lviv, Drahomanova St. 50, 79005 Lviv, Ukraine \\ * Corresponding author. E-mail: kordan50@gmail.com
}

Received October 25, 2019; accepted December 18, 2019; available on-line April 1, 2020 https://doi.org/10.30970/cma12.0396

\begin{abstract}
The electrochemical hydrogenation of $\mathrm{SmNi}_{5-x} M_{x}$ phases $(M=\mathbf{I n}$; $\mathbf{I n}+\mathrm{Sn})$ and the binary compound $\mathrm{SmNi}_{5}$ has been studied for the first time by $\mathrm{X}$-ray diffraction, scanning electron microscopy, energy-dispersive $\mathrm{X}$-ray spectroscopy, and $\mathrm{X}$-ray fluorescence spectroscopy. All these phases crystallize in hexagonal $\mathrm{CaCu}_{5^{-}}$ type structures. The solubility of $\mathrm{In}$ or $\mathrm{In}+\mathrm{Sn}$ in the binary compound $\mathrm{SmNi}_{5}$ is not higher than 5.0-5.5 at.\%, which can be explained by the large difference between the atomic radii of the doping components (In, Sn) and nickel. At charging to the $3 \mathrm{H} / \mathrm{f}$.u. level (current density $1.0 \mathrm{~mA} / \mathrm{cm}^{2}$ ) the electrodes based on the binary, ternary and quaternary phases demonstrated maxima of $2.41,2.52$, and $2.72 \mathrm{H} / \mathrm{f}$.u., respectively. The most geometrically advantageous sites in the initial structures are octahedral voids (Wyckoff position $3 f$ ), where the coordination polyhedron of the $\mathrm{H}$-atom is an octahedron of composition $\left[\mathrm{HSm}_{2} \mathrm{M}_{4}\right]$. The results of the spectral analysis showed that the In-doped electrode lost In in specific interactions of the surface with the electrolyte during the electrochemical process, in contrast to the other electrodes, which are stable (the qualitative and quantitative compositions of the observed phases remained unchanged).
\end{abstract}

X-ray diffraction / Electron microscopy / Solid solutions / $\mathrm{CaCu}_{5}$-type structure / Ni-MH battery / Electrochemical hydrogenation

Introduction

Intermetallic compounds and composites are the basis of new technological materials with interesting and specific physical and chemical properties. Some of them have significant void size and affinity to hydrogen and can be used as hydrogen storage materials and as electrodes in Ni-MH batteries [1,2]. The best hydrogen absorption characteristics have materials developed on the basis of Laves phases (structure types $\mathrm{MgCu}_{2}, \mathrm{MgZn}_{2}, \mathrm{MgNi}_{2}$ ) and multicomponent solid solutions with $\mathrm{CaCu}_{5}, \mathrm{CeNi}_{3}$, $\mathrm{PuNi}_{3}, \quad \mathrm{Th}_{2} \mathrm{Ni}_{17}, \mathrm{U}_{3} \mathrm{Si}_{2}$ (ternary variant $\mathrm{Mo}_{2} \mathrm{FeB}_{2}$ ), $\mathrm{W}_{2} \mathrm{CoB}_{2}$ and some other structure types [3-9]. The study of these compounds is often motivated by the potential influence of hydrogen on the magnetic properties of the materials. Investigations of phases with $\mathrm{CaCu}_{5}$-type structures and improvement of hydrogen sorption properties by doping with $s$ - and $p$-elements are described in [10-22]. The improvement of the corrosion resistance of the electrodes, effective passivity in alkaline solution, thermal stability and absorption capacities of the alloys are also considered.
The $\mathrm{CaCu}_{5}$-type structure (space group $P 6 / \mathrm{mmm}$, Pearson symbol $h P 6$, formula units $Z=1$ ) is a parent type at the origin of a large family of derivatives, such as $\mathrm{Th}_{2} \mathrm{Ni}_{17}$ (hexagonal modification), $\mathrm{Th}_{2} \mathrm{Zn}_{17}$ (rhombohedral modification), $\mathrm{PuNi}_{3}, \mathrm{Gd}_{2} \mathrm{Co}_{7}, \mathrm{CeNi}_{3}$, $\mathrm{Ce}_{2} \mathrm{Ni}_{7}, \quad \mathrm{ThMn}_{12}$, monoclinic phases with 3:29 stoichiometry, $\mathrm{PrNi}_{2} \mathrm{Al}_{3}$ (ternary variant), and others. In this structure the rare-earth elements (large atoms) occupy the site $1 a(000)$, whereas the other two positions, $2 c(1 / 32 / 30)$ and $3 g(1 / 201 / 2)$, are filled by elements with smaller atomic radii. All of the structure types listed above have related frameworks of atoms and void layers that make them applicable for intercalation of small atoms such as hydrogen, boron, carbon, and nitrogen in the structure. The $\mathrm{CaCu}_{5}$-type contains 3 types of void: one octahedral void in Wyckoff position $3 f(1 / 21 / 20)$, and two tetrahedral voids in $3 h(1 / 32 / 3 z)$ and $6 m(x 2 x 1 / 2)$. By gaseous hydrogenation of intermetallics, hydrides with a content of 6-7 H/f.u can be formed. In this case all of the voids are involved (Fig. 1). We expect that at electrochemical hydrogenation the octahedral voids are the first to be occupied by $\mathrm{H}$-atoms, because of 
geometrical and coordination $\left(\left[\mathrm{HSm}_{2} M_{4}\right]\right)$ reasons, similarly as in $R_{2} \mathrm{Fe}_{17} \mathrm{D}_{x}$ [23].

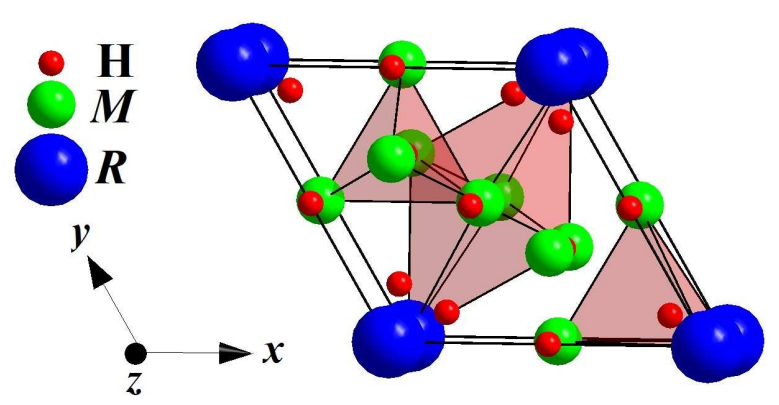

Fig. 1 Unit cell of $R M_{5}$ hydrides (matrix with $\mathrm{CaCu}_{5}$-type structure) and coordination polyhedra of the $\mathrm{H}$-atoms.

Hydrides or deuterides with $\mathrm{Th}_{2} \mathrm{Ni}_{17}$-type structures have been studied by various authors (e.g. [23-26]). Isnard et al. [23] investigated several $R_{2} \mathrm{Fe}_{17} \mathrm{D}_{x}$ deuterides by neutron diffraction and found that the octahedral void site in Wyckoff position $6 h$ is preferred for the hydrides (deuterides). Occupation of the tetrahedral void site in $12 i$ only occurs for higher $\mathrm{H}$ contents $(x>3)$. A similar situation is observed in the case of phases with $\mathrm{CaCu}_{5}$-type structures. Hydrogen insertion into the octahedral voids in the structure is thermodynamically more profitable because of $(a)$ the greater volume of this site and $(b)$ the fact that structural deformations more easily occur when the octahedron vertices are formed by larger atoms, such as rare-earth metals.

The solubility of $p$-elements in $R \mathrm{Ni}_{5}$ depends on the atomic radii of the doping components. If the radius is close to the atomic radius of $\mathrm{Ni}$, the solubility will be maximal and will reach 3 atoms per formula unit. On the contrary, the solubility of indium in the binary compound $\mathrm{TbNi}_{5}$ does not exceed 2 at.\% [27], and the solubility of tin in the $\mathrm{GdNi}_{5}$ compound does not exceed 5-6 at.\% [28].

In our previous papers we reported the solubility of $s$-, $p$ - and $d$-elements in the binary compounds $\mathrm{Tb}_{2} \mathrm{Ni}_{17}$ and $\mathrm{TbCo}_{5}$ [29-32]. Significant improvement of the hydrogen sorption and electrochemical characteristics was observed for these solid solutions. Doping pure magnesium with lithium and aluminum $\left(\mathrm{Mg}_{76} \mathrm{Li}_{12} \mathrm{Al}_{12}\right)$ promotes hydrogen desorption, corrosion resistance, and hydrogen mobility in the solid phase of the electrode [33,34]. In all cases an amorphous solid-state electrode was obtained when a high-density current was used, or hydrogenation up to the maximal hydrogen amount (according to the $\mathrm{H}$-content from gas hydrogenation) was carried out. In order to compare the structural transformations and electrode characteristics (influence of each doping component on the electrochemical behavior of the electrodes) we propose to use non-extreme conditions for the synthesis of hydrides.

The purpose of this research was to study solid solutions based on the intermetallic compound $\mathrm{SmNi}_{5}$ and the influence of In and a mixture of In+Sn doping on the intercalated/deintercalated hydrogen content. We also wanted to study the change of composition of the electrode and surface grain morphology during electrochemical hydrogenation.

\section{Experimental}

Samarium, nickel, tin, and indium with nominal purities of more than 99.9 wt.\% were used as starting materials. Alloys with the compositions $\mathrm{Sm}_{16.7} \mathrm{Ni}_{83.3}$, $\mathrm{Sm}_{16.7} \mathrm{Ni}_{78.3} \mathrm{In}_{5}, \mathrm{Sm}_{16.7} \mathrm{Ni}_{76.8} \mathrm{In}_{6.5}, \mathrm{Sm}_{16.7} \mathrm{Ni}_{78.3} \mathrm{In}_{2.5} \mathrm{Sn}_{2.5}$, and $\mathrm{Sm}_{16.7} \mathrm{Ni}_{76.8} \mathrm{In}_{3.25} \mathrm{Sn}_{3.25}$ were prepared by arc melting of the elements (In with 5 wt.\% excess) under argon atmosphere. To reach homogeneity the samples were sealed in evacuated silica tubes, annealed at $400^{\circ} \mathrm{C}$ for four weeks, and finally quenched in cold water.

Phase analysis of the alloys before and after the electrochemical processes was carried out by powder X-ray diffraction (XRD) using a DRON-2.0M diffractometer (Fe $K \alpha$-radiation) and energydispersive X-ray spectroscopy. Refinement of the lattice parameters (least-squares method) of the observed phases was performed using LATCON [35] and PowderCell [36] programs.

Electrochemical hydrogenation of the binary compound $\mathrm{SmNi}_{5}$ and its ternary and quaternary derivatives $\mathrm{SmNi}_{4.7} \mathrm{In}_{0.3}$ and $\mathrm{SmNi}_{4.7} \mathrm{In}_{0.15} \mathrm{Sn}_{0.15}$ was carried out in 2-electrode Swagelok-type cells. The battery prototype consisted of a negative electrode containing $0.3 \mathrm{~g}$ of the alloy and a positive electrode containing a mixture of dried $\mathrm{Ni}(\mathrm{OH})_{2}$ with 10 wt.\% of graphite added for better electric conductivity. A separator (pressed cellulose) soaked in $6 \mathrm{M} \mathrm{KOH}$ electrolyte was placed between the electrodes. The $E=f(\tau)$ dependence of the batteries was measured in the galvanostatic regime (charging at $3.0 \mathrm{~mA} / \mathrm{cm}^{2}$ and discharging at $1.0 \mathrm{~mA} / \mathrm{cm}^{2}$ ), and over 50 cycles were conducted (galvanostat MTech G410-2 [37]). The optimal current density was selected on the basis of previous experimental work to avoid quick amorphization or other by-processes.

The H-capacity of the electrodes was determined according to Faraday's laws. The H-content is directly proportional to the discharge time (obtained from the $E=f(\tau)$ dependence) and inversely proportional to the amount of substance:

$$
\text { H/f.u. }=\frac{I \cdot \tau}{F \cdot \frac{m}{M}},
$$

$I$ - current, $\tau$ - charge or discharge time, $F$ - Faraday's constant, $m$ - mass, $M-$ molar mass. 
The qualitative and quantitative compositions of the observed phases and the morphology of the material surfaces were examined using scanning electron microscopes TESCAN Vega3 LMU (Oxford Instruments Aztec ONE system) and REMMA-102-02. An X-ray fluorescence spectrometer ElvaX Pro was used for investigation of the composition of the electrode powders before and after hydrogenation.

\section{Results and discussion}

X-ray diffraction of the alloys revealed that the binary $\mathrm{SmNi}_{5}$ sample was single-phase. The $\mathrm{SmNi}_{4.7} \mathrm{In}_{0.3}$ and $\mathrm{SmNi}_{4.7} \mathrm{In}_{0.15} \mathrm{Sn}_{0.15}$ samples were two-phase: a main phase with $\mathrm{Sm}(\mathrm{Ni}, \mathrm{In}, \mathrm{Sn})_{5}$ stoichiometry and a minority ternary phase with $\mathrm{PuNi}_{3}$-type structure. The observed solid solutions crystallize in hexagonal $\mathrm{CaCu}_{5}$-type structures (space group $\mathrm{P6} / \mathrm{mmm}$, Pearson code $h P 6)$. An increase of the unit-cell parameters was observed for the ternary and quaternary phases compared to the pure $\mathrm{SmNi}_{5}$ binary phase (Table 1). This occurs because nickel is partially substituted in the original structure of $\mathrm{SmNi}_{5}$ by indium, or indium with tin, which have larger atomic radii $\left(r_{\text {In }}=1.66 \AA\right.$, $\left.r_{\mathrm{Sn}}=1.62 \AA\right)$ than nickel $\left(r_{\mathrm{Ni}}=1.24 \AA\right)$. This is also the reason why the solubility of $\mathrm{In}$ and $\mathrm{In}+\mathrm{Sn}$ in $\mathrm{SmNi}_{5}$ cannot be large.

SEM-images and compositions from EDX of the $\mathrm{Sm}_{16.7} \mathrm{Ni}_{78.3} \mathrm{In}_{5}$ and $\mathrm{Sm}_{16.7} \mathrm{Ni}_{78.3} \mathrm{In}_{2.5} \mathrm{Sn}_{2.5}$ alloys (TESCAN Vega3 microscope), and the $\mathrm{Sm}_{16.7} \mathrm{Ni}_{76.8} \mathrm{In}_{6.5}$ and $\mathrm{Sm}_{16.7} \mathrm{Ni}_{76.8} \mathrm{In}_{3.25} \mathrm{Sn}_{3.25}$ alloys (REMMA-102-02 microscope), are presented in Fig. 2 and Fig. 3, respectively. The overall compositions of the alloys and element mapping showed that the real content is very close to the nominal composition (Fig. 2). It is worth noting that the surface morphology of the observed phases is similar for the two series of alloys with 5 and 6.5 at.\% nominal content of doping elements, but for the alloys with larger amounts of In or In+Sn we observed a larger amount of $\mathrm{SmNi}_{3-x} M_{x}$ phase with (probably) $\mathrm{PuNi}_{3}$-type structure. $\mathrm{Sm}^{*}$ in two figures indicates trace amounts of a phase on the basis of pure Sm, which had probably not reacted during the synthesis.

The phase diagram of the Sm-Ni binary system [38] shows that the 1:5 phase is in equilibrium with the $\mathrm{Sm}_{5} \mathrm{Ni}_{19}$ phase (structure type $\mathrm{Ce}_{5} \mathrm{Co}_{19}$, space group $R-3 m$ or structure type $\mathrm{Sm}_{5} \mathrm{Co}_{19}$, space group
$P 6_{3} / m m c$ ). The phases with 5:19, 2:7 and 1:3 stoichiometry are often called "Laves- $\mathrm{CaCu}_{5}$ intergrowth phases" and their crystal structures and some of the XRD peaks are similar to those of the 1:5 phase. XRD powder patterns of the studied alloys are presented in Fig. 4 (bottom line). After hydrogenation (top line) the XRD peaks of the main phase are shifted towards the region of smaller angles, showing that hydrogen insertion has taken place. The formation of an amorphous halo in the range near $35^{\circ}$ and significant expansion of the peak profiles were also observed. This is the evidence of partial amorphization of the sample and etching of the grain surfaces.

The effectiveness of the electrochemical hydrogenation of the $\mathrm{SmNi}_{4.7} M_{x} \quad\left(M_{x}=\mathrm{In}_{0.3}\right.$, $\left.\mathrm{In}_{0.15} \mathrm{Sn}_{0.15}\right)$ phases, which served as negative electrode materials, was studied over 50 charge-discharge cycles. The unit-cell volume increased as a result of hydrogen intercalation into the structure (Table 1).

The electrochemical reactions that occur on the electrodes can be presented by the following scheme: $\mathrm{SmNi}_{5}+x \mathrm{H}_{2} \mathrm{O}+x \bar{e}$

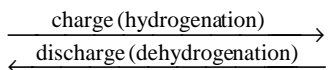

$\mathrm{SmNi}_{5} \mathrm{H}_{x}+x \mathrm{OH}^{-}$

$\mathrm{Ni}(\mathrm{OH})_{2}+x \mathrm{OH}^{-}$

$$
\underset{\text { discharge(reduction) }}{\stackrel{\text { charge(oxidation) }}{\longrightarrow}}
$$

$\mathrm{NiO}(\mathrm{OH})+x \mathrm{H}_{2} \mathrm{O}+x \bar{e}$.

Charging of the battery prototypes with anode materials on the basis of $\mathrm{SmNi}_{5}$ and solid solutions based on $\mathrm{SmNi}_{5}$ was carried out in the galvanostatic regime at $3 \mathrm{~mA} / \mathrm{cm}^{2}$, because this value of current density is optimal for hydrogenation of Ni-based electrodes. For example, hydrogenation of $\mathrm{Mg}$-containing electrodes proceeds better at a lower current density of $0.5-1.0 \mathrm{~mA} / \mathrm{cm}^{2}$ without byprocesses or formation of molecular hydrogen. Charge-discharge characteristics are presented in Fig. 5. During the first nine or ten cycles surface and volume activation occurred. The highest hydrogen content during dehydrogenation was $2.41 \mathrm{H} / \mathrm{f}$.u. for the $\mathrm{SmNi}_{5}$-based electrode, $2.52 \mathrm{H} / \mathrm{f}$.u. for the battery prototype with a ternary phase-based electrode, and $2.72 \mathrm{H} / \mathrm{f}$.u. for the quaternary phase-based electrode. The specific electrical capacity of the studied electrodes did not exceed 140-160 mAh/g. It decreased with increasing number of cycles because of by-processes on the electrode surface.

Table 1 Lattice parameters of the $\operatorname{SmNi}_{5-x} M_{x}(M=\mathrm{In}, \mathrm{In}+\mathrm{Sn})$ phases and their hydrides.

\begin{tabular}{l|c|c|c|c}
\hline \multicolumn{1}{c|}{ Composition } & $a, \AA$ & $c, \AA$ & $V, \AA^{3}$ & $\Delta V / V, \%$ \\
\hline $\mathrm{SmNi}_{5}$ & $4.9240(4)$ & $3.9633(5)$ & $83.21(2)$ & 0.88 \\
$\mathrm{SmNi}_{5} \mathbf{H}_{\boldsymbol{x}}$ & $4.9406(8)$ & $3.9710(8)$ & $83.94(4)$ & \\
$\mathrm{SmNi}_{4.7} \mathrm{In}_{0.3}$ & $4.9288(6)$ & $3.9672(7)$ & $83.46(2)$ & 0.72 \\
$\mathrm{SmNi}_{4.7} \mathrm{In}_{0.3} \mathbf{H}_{x}$ & $4.9430(8)$ & $3.9728(8)$ & $84.06(4)$ & \\
$\mathrm{SmNi}_{4.7} \mathrm{In}_{0.15} \mathrm{Sn}_{0.15}$ & $4.9276(9)$ & $3.9665(8)$ & $83.41(4)$ & 1.07 \\
$\mathrm{SmNi}_{4.7} \mathrm{In}_{0.15} \mathrm{Sn}_{0.15} \mathbf{H}_{\boldsymbol{x}}$ & $4.948(1)$ & $3.976(1)$ & $84.3(1)$ & \\
\hline
\end{tabular}



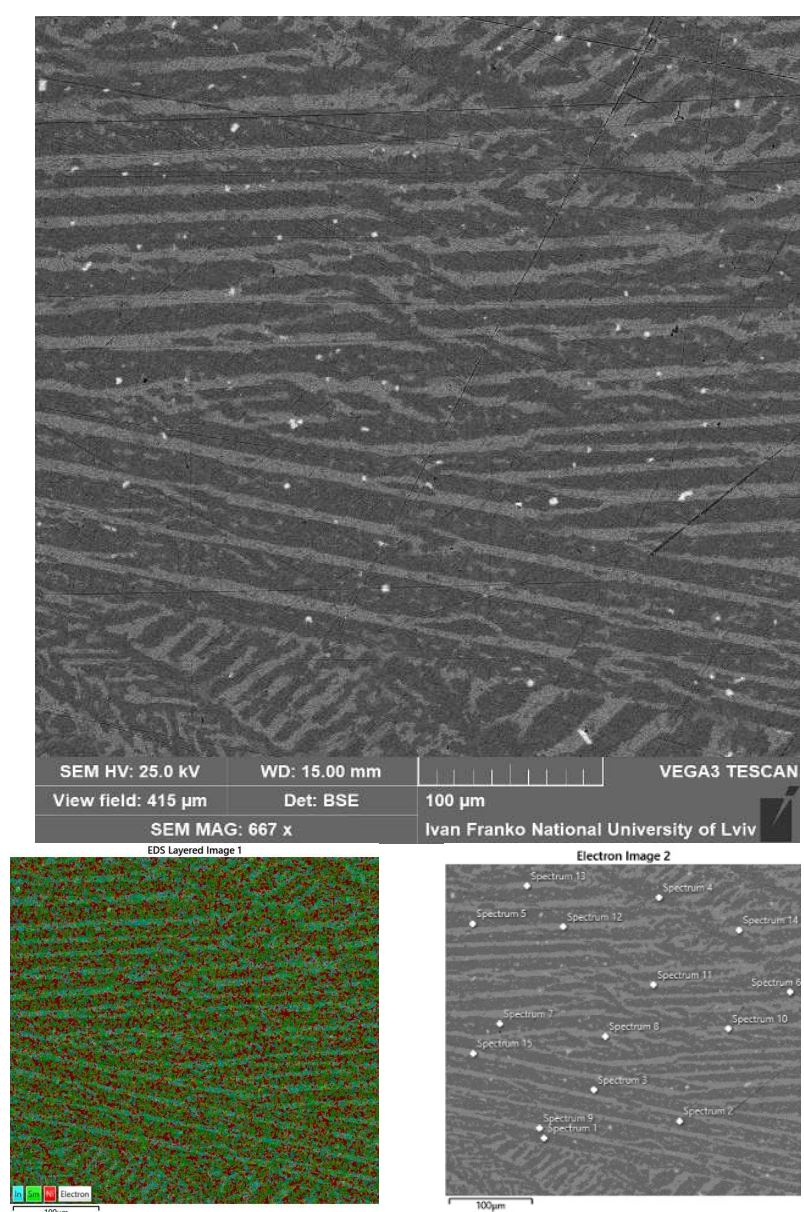

overall composition $-\mathrm{Sm}_{16.8} \mathrm{Ni}_{77.7} \mathrm{In}_{5.5}$

1-5 spectra: $\mathbf{S m}_{17.4(6)} \mathbf{N i}_{\mathbf{7 8 . 0 ( 3 )}} \mathbf{I n}_{\mathbf{4 . 6 ( 3 )}}$;

6-10 spectra: $\mathrm{Sm}_{25.8(3)} \mathrm{Ni}_{68.3(3)} \mathrm{In}_{5.9(5)}$; 11-15 spectra: $\mathrm{Sm}^{*}$.
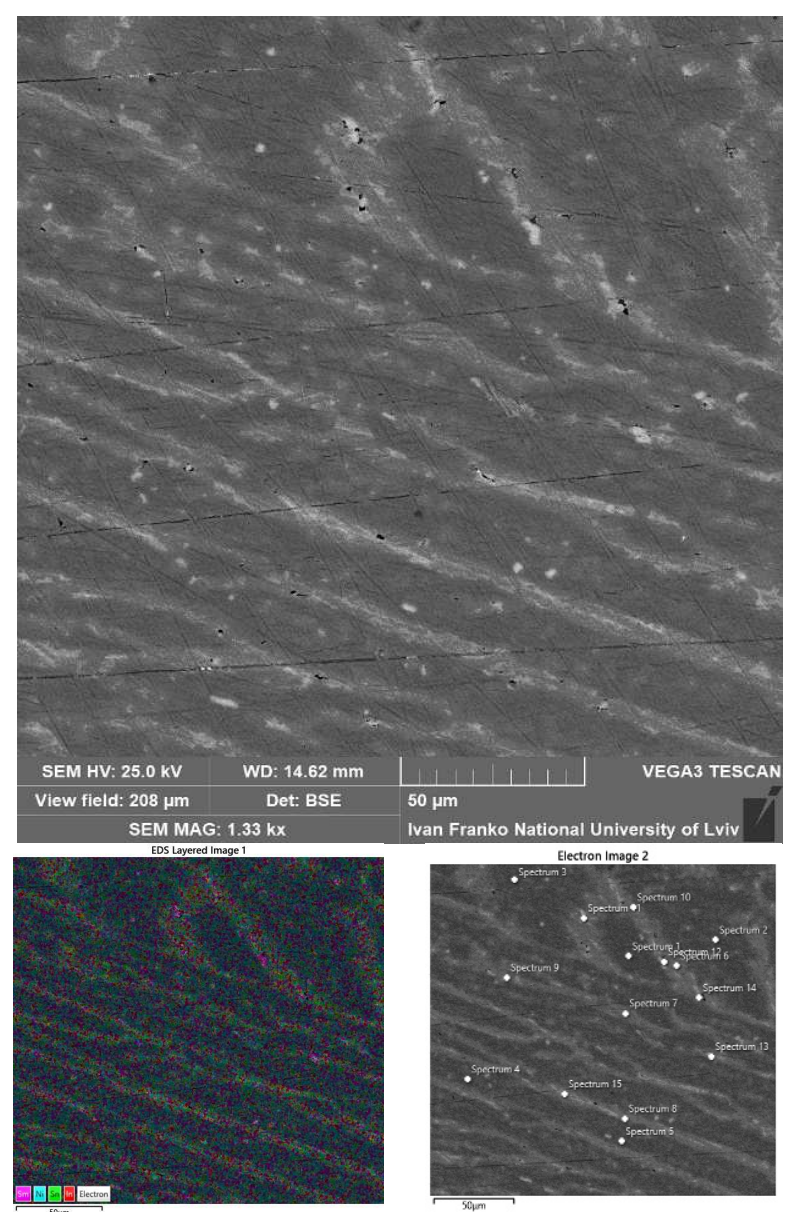

overall composition - $\mathrm{Sm}_{16.9} \mathrm{Ni}_{7.4} \mathrm{In}_{2.7} \mathrm{Sn}_{3.0}$

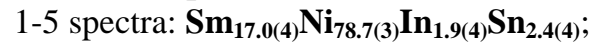
6-10 spectra: $\mathrm{Sm}_{24.3(2)} \mathrm{Ni}_{69.4(6)} \mathrm{In}_{3.0(3)} \mathrm{Sn}_{3.3(4)}$; 11-15 spectra: $\mathrm{Sm}^{*}$.

Fig. 2 Back-scattered electron images of the alloy surface, phase composition and mapping according to the EDX-analysis of $\mathrm{SmNi}_{4.7} \mathrm{In}_{0.3}$ (left) and $\mathrm{SmNi}_{4.7} \mathrm{In}_{0.15} \mathrm{Sn}_{0.15}$ (right) alloys (TESCAN Vega3 LMU microscope).

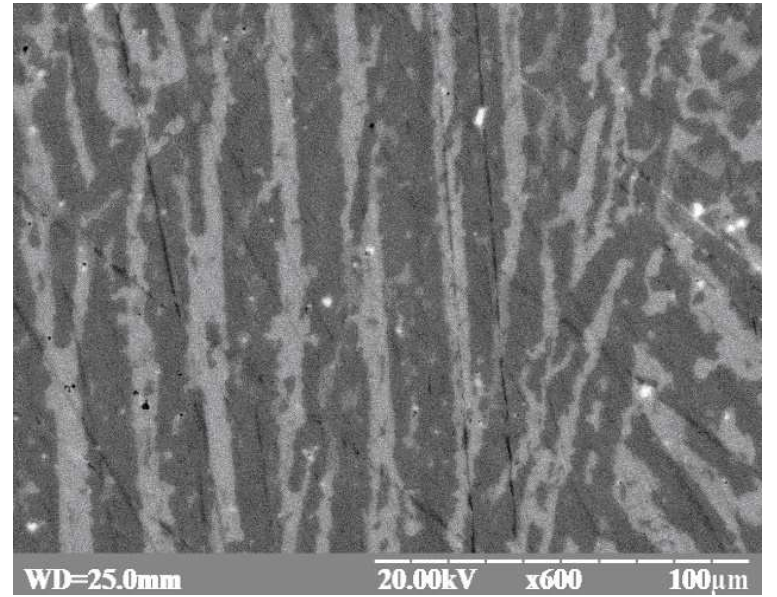

dark phase $-\mathrm{Sm}_{16.5} \mathrm{Ni}_{77.0} \mathrm{In}_{6.5}\left(\mathrm{SmNi}_{5-x} \mathrm{In}_{x}\right)$, gray phase $-\mathrm{Sm}_{25.9} \mathrm{Ni}_{68.8} \mathrm{In}_{5.3}\left(\mathrm{SmNi}_{3-x} \mathrm{In}_{x}\right)$, white phase $-\mathrm{Sm}^{*}$.

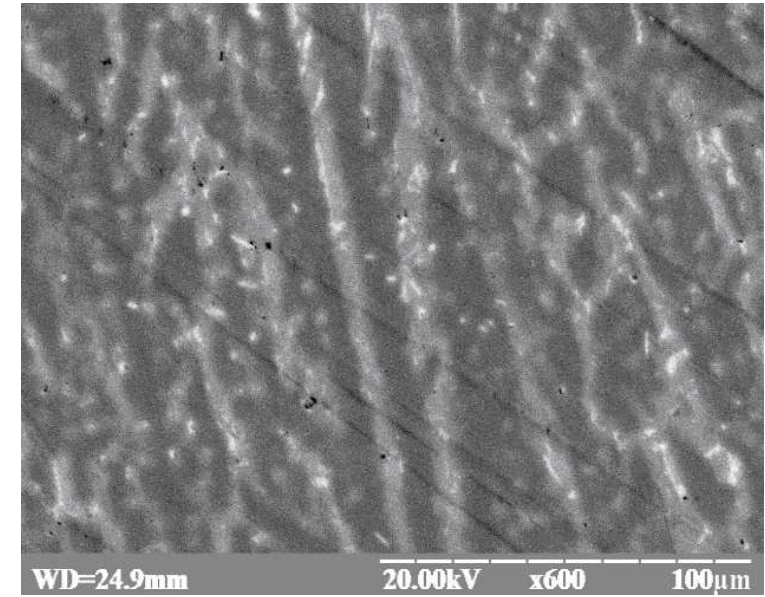

dark phase $-\mathrm{Sm}_{16.3} \mathrm{Ni}_{77.6} \mathrm{In}_{2.8} \mathrm{Sn}_{3.3}\left(\mathrm{SmNi}_{5-x-y} \mathrm{In}_{x} \mathrm{Sn}_{y}\right)$, gray phase $-\mathrm{Sm}_{26.3} \mathrm{Ni}_{69.8} \mathrm{In}_{1.8} \mathrm{Sn}_{2.1}\left(\mathrm{SmNi}_{3-x-y} \mathrm{In}_{x} \mathrm{Sn}_{y}\right)$, white phase $-\mathrm{Sm}^{*}$.

Fig. 3 Back-scattered electron images of the alloy surface and phase composition according to the EDX-analysis of $\mathrm{SmNi}_{4.6} \mathrm{In}_{0.4}$ (left) and $\mathrm{SmNi}_{4.6} \mathrm{In}_{0.20} \mathrm{Sn}_{0.20}$ (right) alloys (REMMA-102-02 microscope). 
V. Kordan et al., Electrochemical hydrogenation of solid solutions based on the intermetallic compound $\mathrm{SmNi}_{5}$

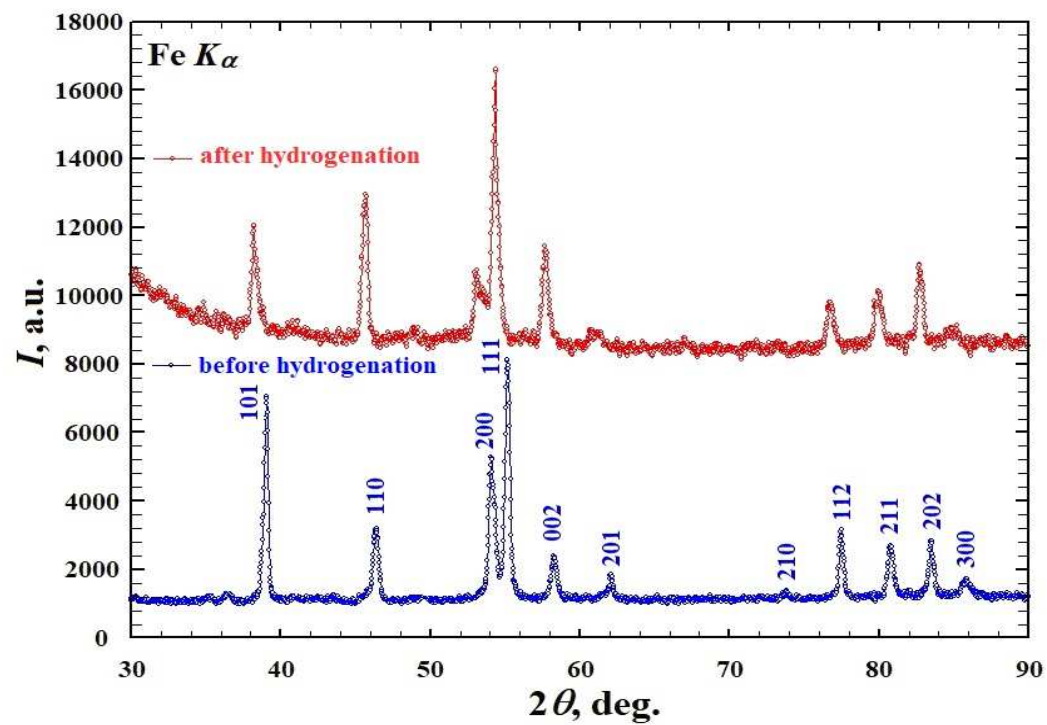

$a$
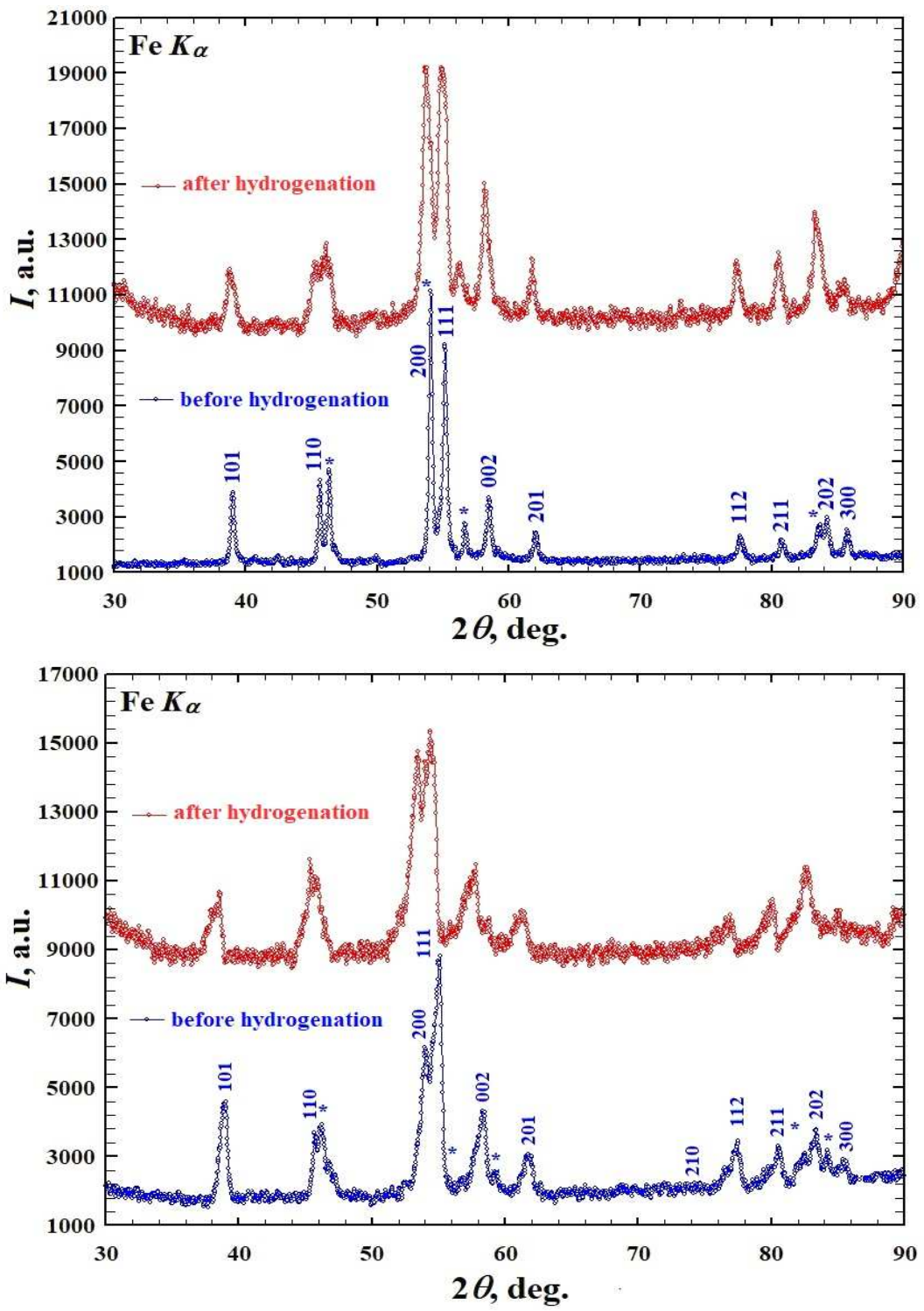

Fig. 4 XRD-powder patterns of the $\mathrm{Sm}_{16.7} \mathrm{Ni}_{83.3}(a), \mathrm{Sm}_{16.7} \mathrm{Ni}_{78.3} \mathrm{In}_{5}(b)$, and $\mathrm{Sm}_{16.7} \mathrm{Ni}_{78.3} \operatorname{In}_{2.5} \operatorname{Sn}_{2.5}(c)$ alloys before (bottom line) and after 51/50 cycles of hydrogenation/dehydrogenation (Miller indexes are indicated; *-impurity). 


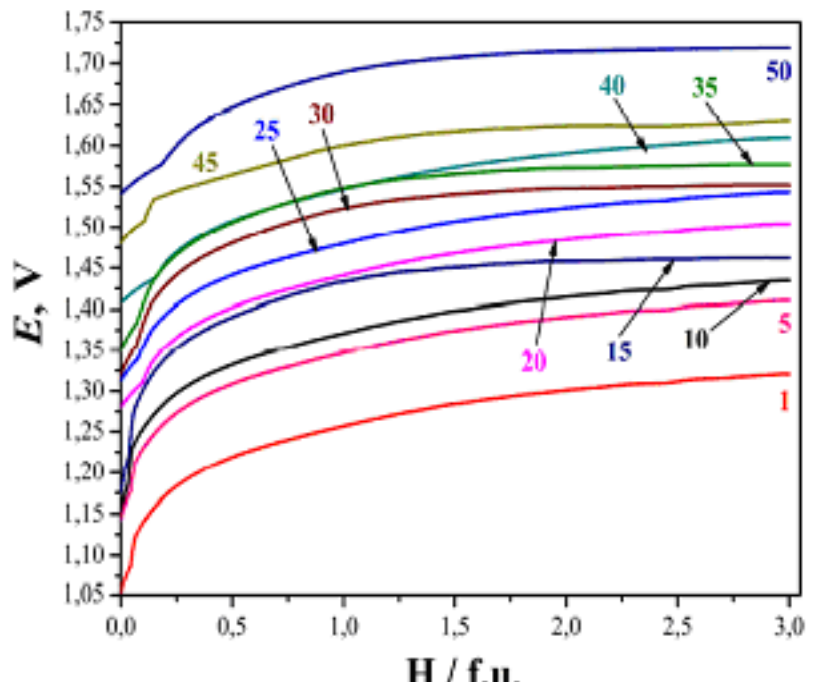

H / f.u.

a

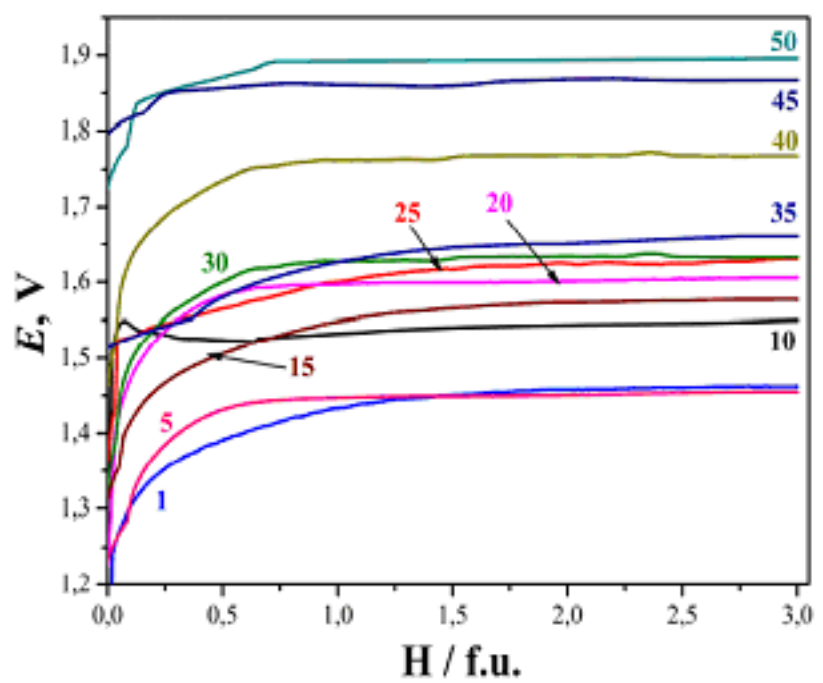

c

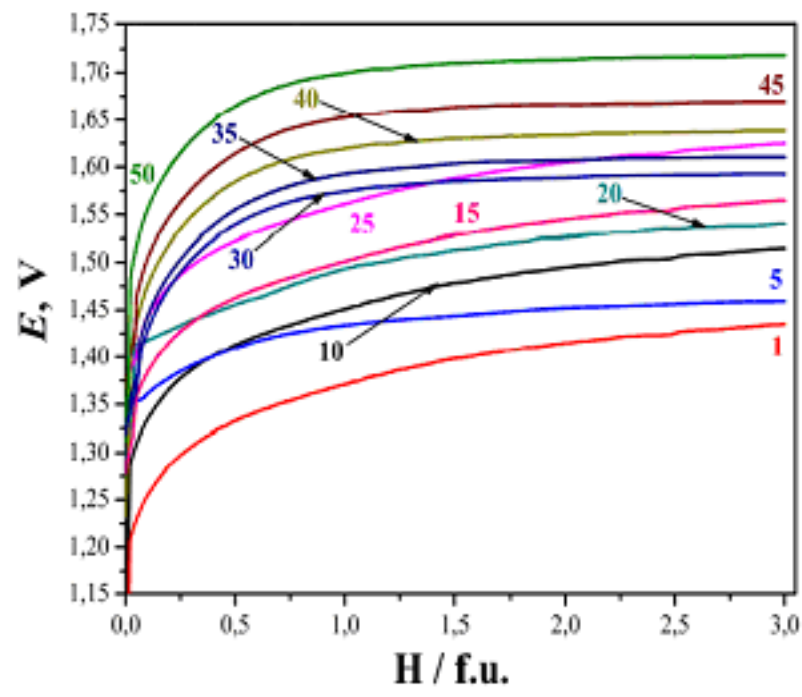

$e$
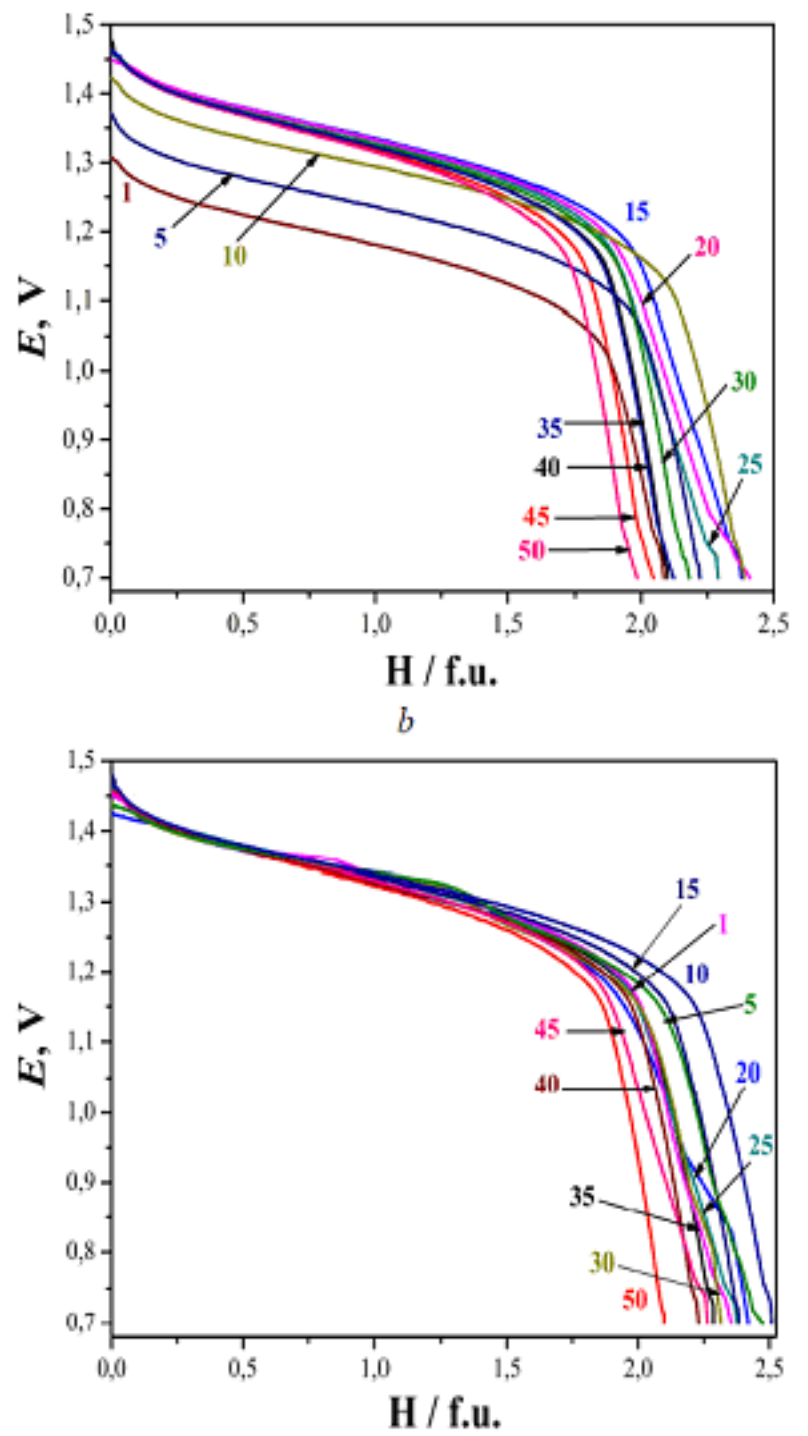

$d$

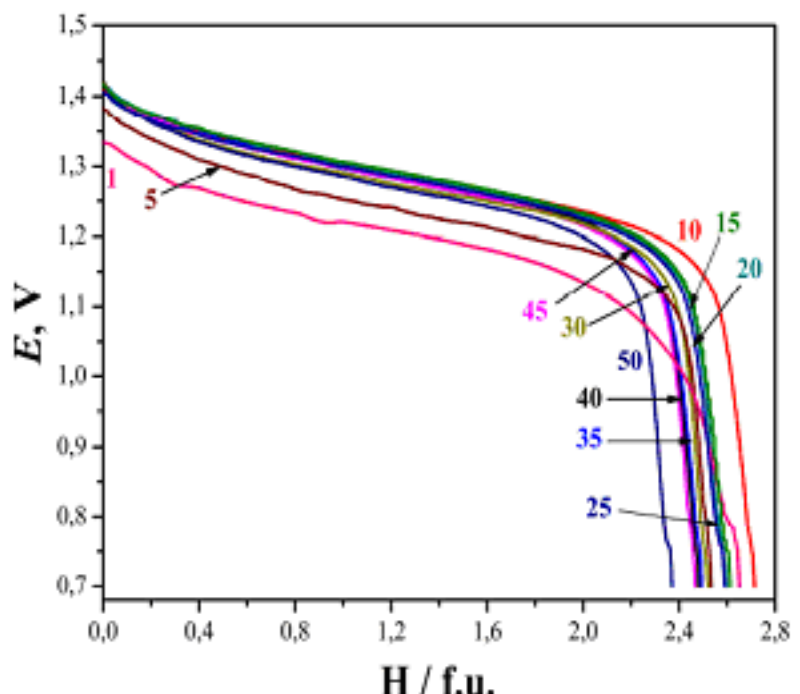

H / f.u.

Fig. 5 Selected charge-discharge curves for the prototype batteries with electrodes based on $\mathrm{Sm}_{16.7} \mathrm{Ni}_{83.3}$ $(a, b), \mathrm{Sm}_{16.7} \mathrm{Ni}_{78.3} \mathrm{In}_{5}(c, d)$, and $\mathrm{Sm}_{16.7} \mathrm{Ni}_{78.3} \mathrm{In}_{2.5} \mathrm{Sn}_{2.5}(e, f)$; the number of the cycle is indicated on the curve. 
The indium-containing electrode is characterized by numerous breaks on the $E$ (volts) versus hydrogen content $\left(\mathrm{H}_{x}\right)$ dependence during charging. The main reason for this is interaction of the surface with the electrolyte and formation of an etched micro-layer on the surface. The decrease of the In content in the solid solution as a result of electrochemical transformations was also observed by the EDX-analysis (Fig. 6). The overall composition of the electrode before and after electrochemical hydrogenation $(51 / 50$ chargedischarge cycles) also confirmed the loss of some amount of indium after contact with the electrolyte under electric charge (Fig. 7).

A similar case with breaks on the charge curves occurs for the electrode based on $\mathrm{SmNi}_{5}$ (Fig. 5a). It can be explained by surface passivation by hydroxideions and formation of a thin film on the basis of metal hydroxides (first plateau). When we apply a larger electric charge, the solid-electrolyte interface (SEI) is destroyed and further $\mathrm{H}$-inclusion can easily occur (the main, almost horizontal line). A battery prototype with a $\mathrm{TbCo}_{5}$-based electrode showed some small plateaus below the main one during discharging [39].

Scanning electron microscopy of the grains also showed a change (grinding) of the surface morphology and grain size of the materials (Fig. 6). The electrodes prepared from the investigated materials were stable in the alkaline solution for more than 50 cycles of charge-discharge, but for the ternary phase $\left(\mathrm{SmNi}_{4.7} \mathrm{In}_{0.3}\right)$ the occurrence of dark regions on the spectra is the evidence of surface corrosion (Fig. 6b,d). The amount of SEI-phases is very low and their structure is often amorphous. This explains why by-products on the basis of oxides or hydroxides were not observed by XRD. The change of the quantitative composition of the quaternary phase $\left(\mathrm{SmNi}_{4.7} \operatorname{In}_{0.15} \mathrm{Sn}_{0.15}\right)$ was not as significant as for the ternary one. In general, the results of the EDX-analysis showed that the solubility of the doping elements was around 5.0-5.5 at.\%.

There are two main reasons why the 4-component alloy shows better results as anode in the Ni-MH battery than the binary and 3-component samples. The first reason lies in the probably better corrosion resistance of the $\mathrm{SmNi}_{4.7} \mathrm{In}_{0.15} \mathrm{Sn}_{0.15}$ alloy in alkaline solution. The second one is the formation of a 5-component $\mathrm{SmNi}_{4.7} \mathrm{In}_{0.15} \mathrm{Sn}_{0.15} \mathrm{H}_{x}$ alloy during hydrogenation, which may be considered as a highentropy system. High-entropy alloys have much better properties than binary, ternary and quaternary alloys based on the same components. We consider that the energy parameter "solid-state entropy" significantly affects the diffusion of hydrogen into the bulk and decreases the activation energy on the electrode surface. A similar case was observed during hydrogenation of a $\mathrm{Tb}_{2} \mathrm{Ni}_{15.2} \mathrm{Li}_{0.6} \mathrm{Mg}_{0.6} \mathrm{Sb}_{0.6}$ alloy with $\mathrm{Th}_{2} \mathrm{Ni}_{17}$-type structure [40].

More detailed analysis of the compositions of the electrodes was carried out using X-ray fluorescence spectroscopy. In Fig. 7 spectra and overall compositions of the samples are presented. All the samples contained a low amount of potassium from the electrolyte $(6 \mathrm{M} \mathrm{KOH})$. The oxygen and potassium contents were removed by internal normalization. Significant changes of composition, partial destruction of the crystal structure and enhanced etching of grains may occur depending on the experimental conditions of hydrogenation. Using a current density of $3.0 \mathrm{~mA} / \mathrm{cm}^{2}$ (Fig. 7a) leads to insignificant changes of the composition (in agreement with the EDX-analysis). If $10.0 \mathrm{~mA} / \mathrm{cm}^{2}$ is used, destruction of the intermetallic phase occurs very fast and the electric charge promotes surface dissolution in the electrolyte environment.

The maximal amount of intercalated hydrogen was not reached under the conditions of our experiment. In the case of electrochemical hydrogenation, the $\mathrm{H}$ atoms occupy the void site $3 f$ of the structure, while in the case of gas hydrogenation they occupy the same octahedral voids $3 f$ but also tetrahedral sites in $3 h$ and 6m. Biliskov et al. [41] investigated the $\mathrm{SmNi}_{5-x} \mathrm{Al}_{x}$ series submitted to gas and electrochemical hydrogenation. The hydrogen content decreased from $\sim 5$ to $\sim 3 \mathrm{H} /$ f.u. with increasing aluminum content (gas hydrogenation), and the formation of $\sim 100 \mathrm{~nm}$-large nanoparticles was observed. The largest amount of hydrogen could be inserted by gas hydrogenation at high pressure. Similar results for hydrides based on the $\mathrm{SmNi}_{5-x} \mathrm{Ga}_{x}$ solid solutions are presented in [42].

\section{Conclusion}

The $\mathrm{SmNi}_{4.7} \mathrm{In}_{0.3}$ and $\mathrm{SmNi}_{4.7} \mathrm{In}_{0.15} \mathrm{Sn}_{0.15}$ phases crystallize in $\mathrm{CaCu}_{5}$-type structures. The maximal solubility of $\mathrm{In}$ and $\mathrm{In}+\mathrm{Sn}$ in binary $\mathrm{SmNi}_{5}$ does not exceed 5.0-5.5 at.\%. The low solubility can be explained by the large differences between the atomic radii of the $p$-elements and nickel. According to SEM and EDX-analysis the secondary phase in the alloys can have $5: 19,2: 7$ or $1: 3$ stoichiometry. These "Laves- $\mathrm{CaCu}_{5}$ intergrowth phases" are related to the 1:5 phase with $\mathrm{CaCu}_{5}$-type structure.

At charging to $3 \mathrm{H} / \mathrm{f} . \mathrm{u}$. (current density $1.0 \mathrm{~mA} / \mathrm{cm}^{2}$ ) the hydrogen content reached a maximum of $2.41 \mathrm{H} / \mathrm{f}$.u. for the two-component electrode $\left(\mathrm{SmNi}_{5}\right), 2.52 \mathrm{H} / \mathrm{f} . \mathrm{u}$. for the threecomponent electrode and $2.72 \mathrm{H} / \mathrm{f} . \mathrm{u}$. for the quaternary phase-based electrode. The current efficiency was in the range $80-91 \%$. The most geometrically advantageous sites for $\mathrm{H}$-inclusion are octahedral voids (Wyckoff position $3 f$ ) formed by four atoms of nickel, or a statistical mixture of atoms, in the equatorial plane and two samarium atoms at the vertices above and below this plane. The coordination polyhedron for the H-atoms is $\left[\underline{\mathrm{H} S m}{ }_{2} M_{4}\right]$. The $\mathrm{SmNi}_{4.7} \mathrm{In}_{0.15} \mathrm{Sn}_{0.15}$ alloy showed better corrosion resistance in the alkaline solution and did not undergo significant losses of $p$-element during hydrogenation, as was the case for $\mathrm{SmNi}_{4.7} \operatorname{In}_{0.3}$. 

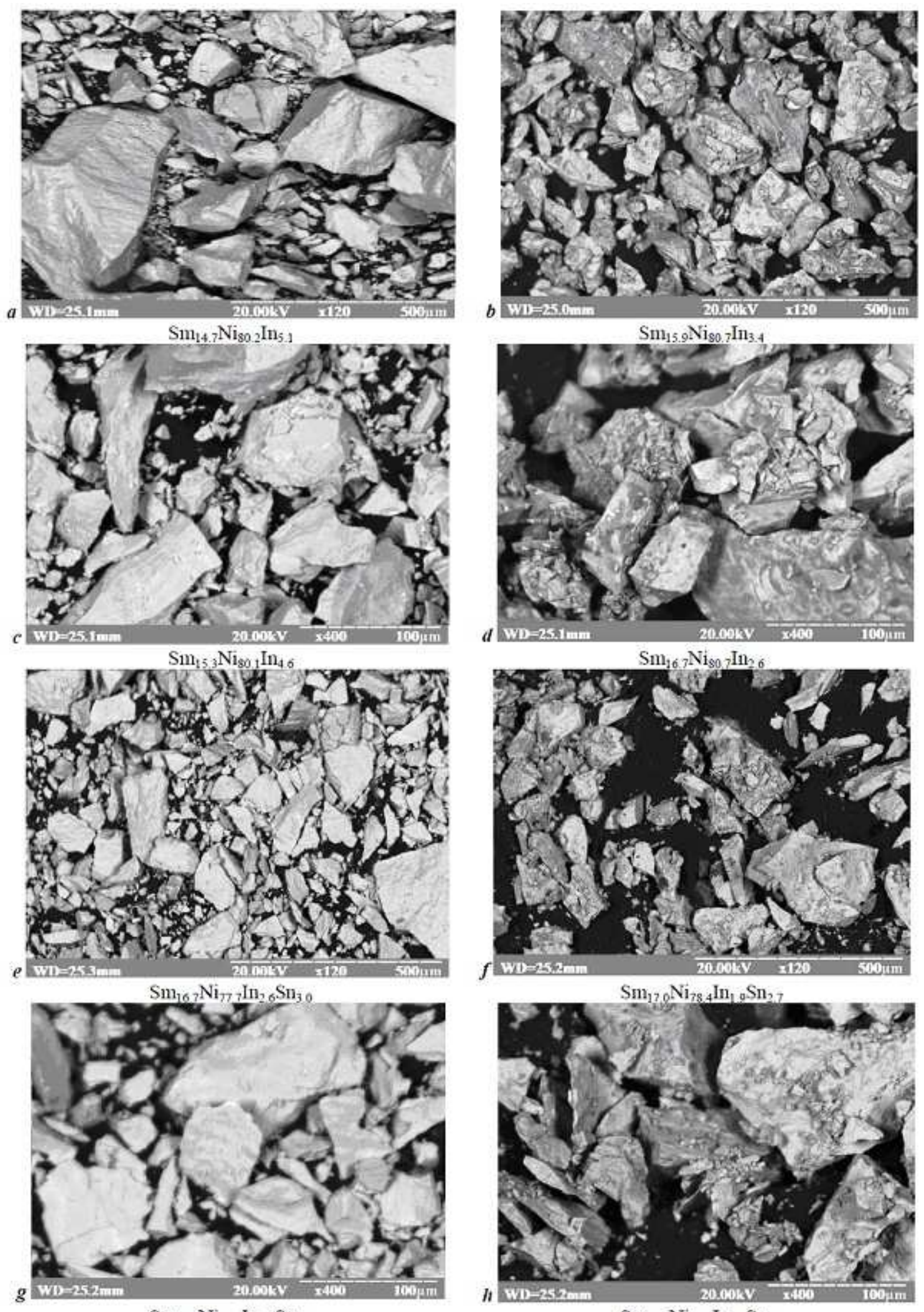

$\mathrm{Sm}_{17.4} \mathrm{Ni}_{77.4} \mathrm{In}_{2.3} \mathrm{Sn}_{2.9}$

Fig. 6 SEM-images of the anode material powders: $\operatorname{SmNi}_{4.7} \operatorname{In}_{0.3}(a-d)$ and $\operatorname{SmNi}_{4.7} \operatorname{In}_{0.15} \operatorname{Sn}_{0.15}(e-h)$ before (left) and after (right) 51/50 cycles of electrochemical hydrogenation/dehydrogenation (REMMA-102-02 microscope). 

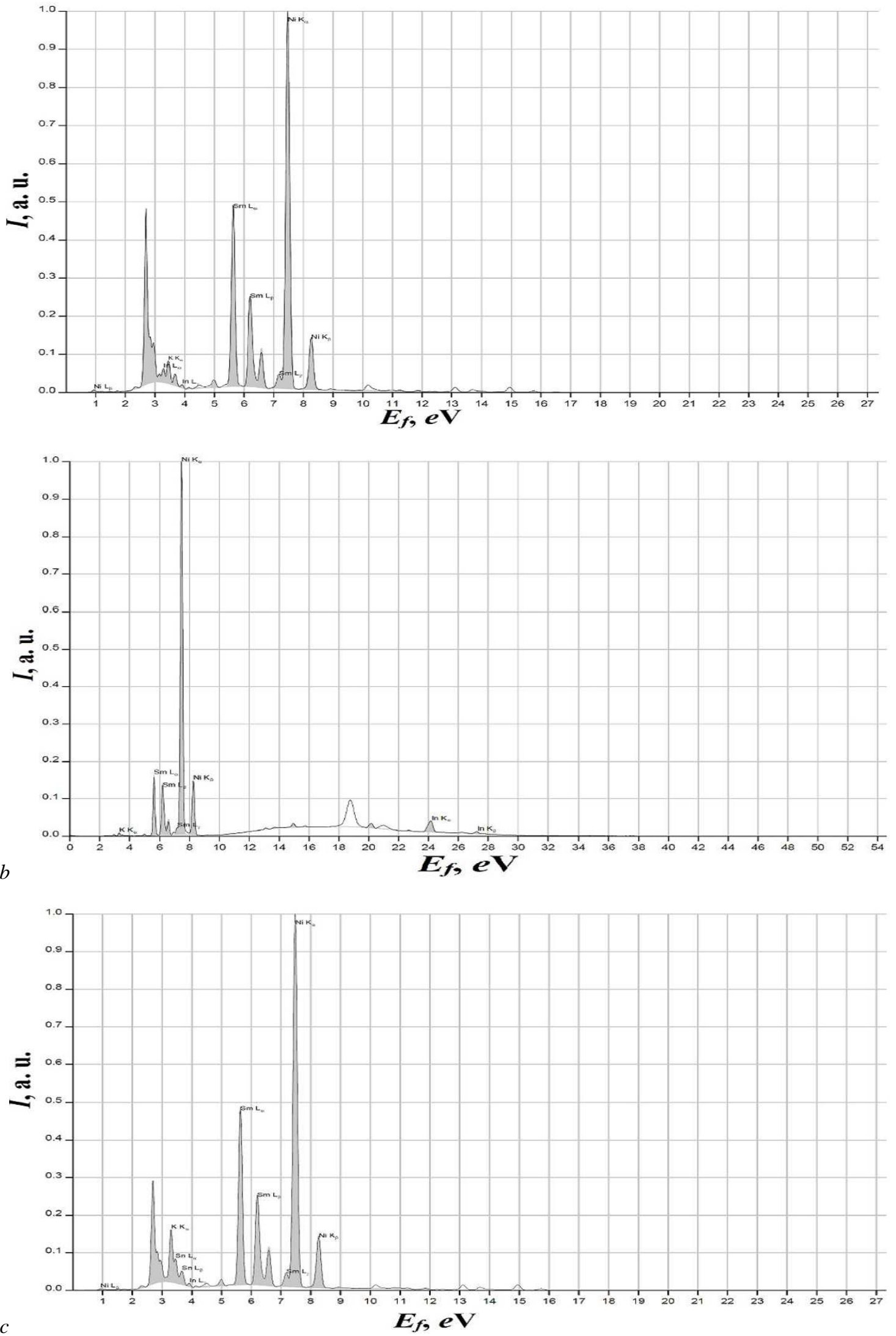

Fig. 7 X-ray fluorescence spectra after charge-discharge cycles of electrodes based on $\operatorname{SmNi}_{4.7} \operatorname{In}_{0.3}(a)$ and $\mathrm{SmNi}_{4.7} \mathrm{In}_{0.15} \mathrm{Sn}_{0.15}$ (c) (current density 3.0/1.0 mA/cm ${ }^{2}$ ) and $\mathrm{SmNi}_{4.7} \mathrm{In}_{0.3}$ (b) (current density $10.0 / 1.0 \mathrm{~mA} / \mathrm{cm}^{2}$ ). Compositions without potassium and oxygen were $\mathrm{Sm}_{17.0} \mathrm{Ni}_{80.7} \mathrm{In}_{2.3}, \mathrm{Sm}_{16.4} \mathrm{Ni}_{78.9} \mathrm{In}_{2.1} \mathrm{Sn}_{2.6}$, and $\mathrm{Sm}_{8.3} \mathrm{Ni}_{91.3} \mathrm{In}_{0.4}$, respectively. 
The hydride $\mathrm{SmNi}_{4.7} \mathrm{In}_{0.15} \mathrm{Sn}_{0.15} \mathrm{H}_{x}$ can be considered as a high-entropy system and demonstrates the best H-diffusion (mobility) into the bulk of the electrode. Comparing the electrochemical behavior of the studied alloys we can conclude that $\mathrm{SmNi}_{5-x} M_{x}$ phases are perspective materials for negative electrodes in Ni-MH batteries.

\section{Acknowledgements}

This work was supported by the Ministry of Education and Science of Ukraine (grant No. 0117U007192).

\section{References}

[1] J.O. Besenhard, Handbook of Battery Materials, Wiley-VCH, Weinheim, 1999, 1023 p.

[2] C.A. Vincent, B. Scrosati, Modern Batteries: An Introduction to Electrochemical Power Sources: 2nd Ed., Arnold, London, 1997, 351 p.

[3] M.H. Mintz, I. Jacob, D. Shaltiel, Experimental Techniques II: Adaptation of New Techniques to Study Surface and Bulk Properties of H-Metal Systems, In: L. Schlapbach (Ed.), Hydrogen in Intermetallic Compounds II, Springer, Berlin, 1992, pp. 285-317.

[4] J.M. Ogden, Int. J. Hydrogen Energy 24 (8) (1999) 709-730.

[5] R.C. Weast, M.J. Astle, W.H. Beyer, $C R C$ Handbook of Chemistry and Physics: 64th Ed., CRC Press, Boca Raton, FL, 1983, 2303 p.

[6] K. Miliyanchuk, L. Havela, R. Gladyshevskii, Chem. Met. Alloys 12(1/2) (2019) 16-20.

[7] N. Chorna, N. Sagan, O. Zelinska, V. Kordan, A. Zelinskiy, V. Pavlyuk, Chem. Met. Alloys 11(1/2) (2018) 27-33.

[8] K. Miliyanchuk, S. Maskova, L. Havela, R. Gladyshevskii, Chem. Met. Alloys 9(3/4) (2016) 169-173.

[9] L. Havela, S. Maskova, P. Svoboda, K. Miliyanchuk, A. Kolomiets, A.V. Andreev, Chem. Met. Alloys 6(3/4) (2013) 170-176.

[10] A. Stetskiv, B. Rozdzynska-Kiełbik, G. Kowalczyk, W. Prochwicz, P. Siemion, V. Pavlyuk, Solid State Sci. 38 (2014) 35-41.

[11] K. Giza, W. Iwasieczko, V.V. Pavlyuk, H. Bala, H. Drulis, L. Adamczyk, J. Alloys Compd. 429 (2007) 352-356.

[12] L. Wang, H. Yuan, H. Yang, K. Zhou, D. Song, Y. Zhang, J. Alloys Compd. 302 (2000) 65-69.

[13] A. Percheron-Guegan, C. Lartigue, J.C. Achard, P. Germi, F. Tasset, J. Less Common Met. 74 (1980) 1-12.

[14] J.M. Joubert, M. Latroche, R. Cerny, R.C. Bowman Jr., A. Percheron-Guégan, K. Yvon, J. Alloys Compd. 293-295 (1999) 124-129.
[15] J.M. Joubert, M. Latroche, R.C. Bowman Jr., A. Percheron-Guégan, F. Bourée-Vigneron, Appl. Phys. A 74 (Suppl. 1) (2002) 1037-1039.

[16] K. Giza, W. Iwasieczko, V.V. Pavlyuk, H. Bala, H. Drulis, J. Power Sources 181 (2008) 38-40.

[17] V.V. Pavlyuk, I.M. Opainych, O.I. Bodak, T. Palasinska, B. Rozdzynska, H. Bala, Pol. J. Chem. 71 (1997) 309-313.

[18] S. De Negri, P. Solokha, A. Saccone, V. Pavlyuk, Intermetallics 16 (2008) 168-178.

[19] B. Rozdzynska-Kielbik, W. Iwasieczko, H. Drulis, V.V. Pavlyuk, H. Bala, J. Alloys Compd. 298 (2000) 237-243.

[20] K. Giza, H. Bala, V.V. Pavlyuk, Mater. Corros. 60 (2009) 29-33.

[21] K. Giza, W. Iwasieczko, H. Bala, V.V. Pavlyuk, H. Drulis, Int. J. Hydrogen Energy 34 (2009) 913-915.

[22] O.Ya. Makaryk, G.S. Dmytriv, D.G. Kevorkov, V.V. Pavlyuk, J. Alloys Compd. 317-318 (2001) 448-449.

[23] O. Isnard, S. Miraglia, J.L. Soubeyroux, D. Fruchart, A. Stergiou, J. Less-Common Met. 162(2) (1990) 273-284.

[24] V. Levytskyy, V. Babizhetskyy, O. Myakush, B. Kotur, I. Koval'chuk, Chem. Met. Alloys 7 (2014) 26-31.

[25] I. Tereshina, S. Nikitin, W. Suski, J. StepienDamm, W. Iwasieczko, H. Drulis, K. Skokov, J. Alloys Compd. 404-406 (2005) 172-175.

[26] S. Wirth, R. Skomski, J.M.D. Coey, Phys. Rev. B 55 (1997) 5700-5707.

[27] M. Dzevenko, Yu. Tyvanchuk, K. Demidova, M. Lukachuk, Ya. Kalychak, Visn. Lviv. Univer., Ser. Khim. 55(1) (2014) 21-28 (in Ukrainian).

[28] L. Romaka, V.V. Romaka, Yu. Stadnyk, P. Demchenko, J. Alloys Compd. 505 (2010) 7075.

[29] V. Kordan, V. Nytka, G. Kovalczyk, A. Balinska, O. Zelinska, R. Serkiz, V. Pavlyuk, Chem. Met. Alloys 10(2) (2017) 61-68.

[30] V. Kordan, O. Zelinska, V. Pavlyuk, V. Nytka, R. Serkiz, Chem. Met. Alloys 9(3/4) (2016) 153-157.

[31] I. Tarasiuk, I. Stetskiv, V. Kordan, V. Pavlyuk, Visn. Lviv. Univer., Ser. Khim. 58(1) (2017) 117-123 (in Ukrainian).

[32] V. Kordan, V. Nytka, I. Tarasiuk, O. Zelinska, R. Serkiz, V. Pavlyuk, Visn. Lviv. Univer., Ser. Khim. (in press).

[33] Pavlyuk, W.Ciesielski, N. Pavlyuk, D. Kulawik, M. Szyrej, B. Rozdzynska-Kielbik, V. Kordan, Ionics 25(6) (2018) 2701-2709.

[34] V. Pavlyuk, W. Ciesielski, N. Pavlyuk, D. Kulawik, G. Kowalczyk, A. Balińska, M. Szyrej, B. Rozdzynska-Kielbik, A. Folentarska, V. Kordan, Mater. Chem. Phys. 223 (2019) 503-511.

[35] G. King, D. Schwarzenbach, Latcon. Xtal 3.7 System, University of Western Australia, 2000. 
V. Kordan et al., Electrochemical hydrogenation of solid solutions based on the intermetallic compound $\mathrm{SmNi}_{5}$

[36] W. Kraus, G. Nolze, Powder Cell for Windows, Berlin, 1999.

[37] http://chem.lnu.edu.ua/mtech/mtech.htm.

[38] Y.Y. Pan, C.S. Cheng, Acta Phys. Sin. 32(1) (1983) 92-95 (in Chinese).

[39] I. Stetskiv, V. Kordan, I. Tarasiuk, V. Pavlyuk, Coll. Abstr. XVII Sci. Conf. "Lviv Chemical Readings - 2019”, Lviv, 2019, p. H2 (in Ukrainian).
[40] V. Kordan, O. Zelinska, I. Tarasiuk, R. Serkiz, V. Pavlyuk, Book Abstr. XXI-th ISPCS21, Czestochowa, 2018, p. 73.

[41] N. Biliskov, G.I. Miletic, A. Drasner, K. Prezelj, Int. J. Hydrogen Energy 40(27) (2015) 8548-8561.

[42] N. Biliskov, G.I. Miletic, A. Drasner, Int. J. Hydrogen Energy 38(27) (2013) 12213-12222. 